\title{
JUURNAL_RU
}

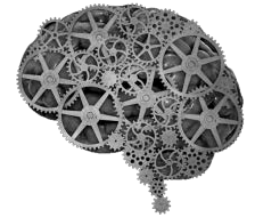

COMPANY GROUP "INTELLEKT"

Жирякова А.Д.
Национальный исследовательский университет «МИЭТ» Москва, Россия

doi: 10.18411/lj2016-8-2-06

idsp 000001: lj2016-17-2-06

\section{Проблемы дизайн-формы в контексте пантехнократической мировоззренческой модели}

Аннотация. В статье рассматриваются вопросы актуализации современных проблем формообразования в дизайне в контекстной соотнесённости с идеями пантехнократического мироустройства. Обосновывается необходимость структурированного подхода к определению дизайна как феномена культуры в рамках означенного контекста. Исследуется влияние формотворческих идей русского авангарда на проблемы Формы в условиях её кризиса, обозначенного тенденцией к минимизации и дематериализации, ставших возможными в рамках существующего технологического уклада.

Ключевые слова. Дизайн-форма, формообразование в промышленном дизайне, пантехнократия, минимизация, дематериализация, русский авнгард, форма-контрформа, ноль-форма.

Проектирование в промышленном дизайне при всей кажущейся однозначности стоящих перед профессионалом-дизайнером задач включает в себя множество проблем, связанных как с самим дизайном, феноменом культуры, так и с различными вызовами современности. В этой связи основными материалами, избранными для исследования являются практические результаты дизайн-проектирования ряда современных и классических авторов (дизайнеров и архитекторов), обозначенные в них тенденции формообразования, модные течения формального характера, влияющие на процессы стилеобразования в дизайне. В качестве примера были выбраны работы Захи 
Хадид в области дизайна и идеи «хорошего» дизайна Диттера Рамса и его последователя Джонатана Айва, как наиболее ярко и контрастно проявляющие тенденции и проблемы Формы [13]. Вопросы теории дизайна рассматриваются в статье в современном культурологическом контексте, с опорой на ряд значимых исследований зарубежных и отечественных авторов (В. Гропиус, Т. Мальдонадо, Ле Корбюзье, М. Билл, В. Ф. Сидоренко, В. Р. Аронов, С. О. Хан-Магомедов, Г. Г. Курьерова и другие).

Неоднократные попытки дать однозначное определение дизайну как виду деятельности [2] нельзя считать успешными, на наш взгляд, по причине их статичной фиксированности. Дизайн встроен в культуру, неотделим от неё и все происходящие в ней изменения, оказывают на него влияние, что порой мы видим настолько разные его проявления, позволяющие говорить о казалось бы, различных видах деятельности, которые невозможно однозначно определить [4]. По нашему мнению, определение дизайна как вида деятельности, его местоположения в современной культуре требует дизайнерского же решения этой задачи, путём структурирования проблемы и структурного определения его частей, составляющих единое целое данного вида деятельности. Закономерный вопрос, какова цель этого действия лежит в поле профессиональных проблем формообразования, поскольку формотворчество один из синонимов дизайна, во всяком случае, его важнейшая часть. Через проблему Формы и различные способы её решения происходит связь с инструментальной составляющей дизайна, что напрямую выводит на существующий уровень развития науки, техники и культуры. Таким образом, дизайн как условная модель, структурно подразделяется на формально-инструментальную и на ментальноидеологическую составляющие.

Парадигма пантехнократии и современная мировоззренческая модель, эксплуатирующая идеи макиавеллизма являются контекстом существования дизайна сегодня. Технократический тренд является источником фетишизации «новизны» в подходе к формированию предметного окружения. Что в свою очередь обусловлено и продиктовано идеологией консюмеризма, низводящего научную новизну до новизны потребительской, по своей сути, являющейся псевдоновизной. С точки зрения проблем Формы в дизайне, её проектного воплощения, перечисленные факторы: уровень инструментального развития, 
технократическое мировоззрение, глобальное потребительство являются контекстами осуществления проектной деятельности в дизайне и существования дизайна как целостного явления. Технический прогресс, по определению стремящийся к новизне, лежит в основе постоянного конфликта формыконстанты, определённой идеологией антропоцентризма и новой формы, поиск которой лежит в области попыток преодоления объективной реальности. Современный Потребитель ждёт от дизайнера чуда невозможного в возможном. Дизайн, превратившийся в конвейер по производству чудес на постоянной основе, рискует быть банальным. Наивность потребителя и технологии маркетинга позволяют сохранять лицо и продолжать транслировать производство чудес в массовом порядке. В этой связи попытки объявить параметризм от Захи Хадид и её сторонников и последователей чудесным явлением абсолютной новизны вполне укладываются в старые как мир отработанные коммерческие схемы. Если же подходить к анализу изделия как формальной целостности, то чудо криволинейной избыточности укладывается в рамки технологических новаций. Новизна в данном случае имеет буквальный смысл - по праву первенства применения технологий NURBS и Безье в создании замысловатых оболочек. Однако талантливость, неповторимость авторского жеста Хадид основывается, прежде всего, на интуитивно, как и полагается, прочувствованной композиции, пропорциях, ритме. На старых добрых, традиционных методах формообразования, рождённых и развитых в «трудовых усилиях» [1]. Но оторванность приёмов, полученных в процессе антропогенеза, от реальности гравитации создаёт иллюзию её преодоления, которая всё же остаётся лишь иллюзией. В сравнении с «чудесным» порывом параметризма «хороший» дизайн Диттера Рамса, транслированный Айвом [11] не покажется ли слишком скучным, рассудочным и приземлённым? Казалось бы, какой простой и однозначный на первый взгляд вопрос. Стремление к идеальности формы, невероятная точность сопряжения элементов, тончайшие отверстия по технологии лазерной резки, сама формальная скупость и идеально выстроенные соотношения целого и частей, особенная дружелюбность к потребителю столь высокого порядка, что кажется царственной снисходительностью, на наш взгляд явление подлинно космического порядка, а избыточность бутофорской криволинейности - немножко дисней-лэнд от дизайна. 
Криволинейная избыточность и скупость геометризма формальных воплощений определяется в рамках инструментальной оппозиции hardlinesoftline, обозначающей инвариант формообразования [6]. Различные попытки дематериализовать формальную субстанциональность ограничиваются присутствием автора и его изделия в том или ином контексте реальности. Наивысший уровень внеконтекстуальности Формы был достигнут в концепциях Русского авангарда [5]. Возможность экстраполяции формальных находок вековой давности на современные проблемы Формы в дизайне основывается на неисчерпаемом формообразующем потенциале русского авангарда. Дематериализация формы - главное ожидаемое «чудо» современности. Наблюдается сдвиг оценочных позиций формы, как результата проектных усилий дизайнера в сторону парадоксальной подмены: «формы нет»-хорошо, форма есть - несовременно, плохо. Здесь уместно вспомнить эпатажное заявления Ф. Старка об исчезновении формы, а с нею, и профессии дизайнера. [14].

Футуристам принадлежит первенство отрицания «старой» литературной формы, [7] что на Российской почве приобретало особое звучание, по причине значимости слова в русской культуре [10]. Это открывало дорогу поиску «новой» формы не только в изобразительных и пластических искусствах, но и способствовало появлению нового вида деятельности - дизайна, во всяком случае, в его концептуальном воплощении. За гибелью «старой» формы последовало рождение новизны. Король умер, да здравствует король!

Тема изготовления чрезвычайно маленького предмета и тема исчезновения формальной субстанциональности стара как мир. Маленькое сохраняло все атрибуты большого. Неважно, что формы «почти» нет, по причине трудности визуального восприятия. Здесь главное чудесное воплощение всех формальных качеств в миниатюре. Исчезновение-невидимость сохраняло форму в полном объёме, лишь была невидима для глаза, сохраняя прежний объём и конфигурацию. Человек-невидимка Герберта Уэлса с помощью косметических средств, одежды, бинтов визуализировал оболочку, форму-кожух.

Современное технологическое достижение - получение материала, имеющего два измерения, а третье равное «толщине» атомарной решётки графена - важный этап в преодолении трёхмерности [12]. Здесь уместно 
сравнение с Чёрным квадратом Малевича, обозначившим модульную универсальную единицу формы вне масштаба. Двухмерность заключает в себе многослойность, как залог трёхмерности. Чёрный квадрат как точка преодоления «старой» формы и провозвестник новизны, своего рода «ноль форма» новой эры, актуализируется в сопоставлении с чёрными глянцевыми экранами электронных устройств. Форма, пройдя через «ноль-форму», воплотилась в идеи новой формы беспредметной всеобщности антифункционалистской концепции супрематизма [3].

«Мы ставим глаз под контроль осязания» [9]. Идея В.Е. Татлина об особом статусе осязания является связующим звеном авангардных концепций формообразования с актуальными поисками соответствия формы и технических инноваций. Форма не видима, но осязаема, тактильно ощущаема, лежит в области предположения и представления. Таким образом, формовосприятие переходит в область чувственного.

Сценарный подход - современный способ реализации проектирования Формы. По В.Ф. Сидоренко «на границе преодоления материала» «форма встречается с контрформой» [8].

Татлин говорил, что соединение художественной интуиции с техникой [10], позволит достигать формального совершенства предметного окружения. Для Татлина проблемы формообразования решались через непосредственное соприкосновение с субъектом. Полная формально-эстетическая гармония изделия и человека определяется именно человеческим фактором.

Современный технологический уклад, направленный на дематериализацию формальных качеств предметного окружения человека рассматривается нами как кризис формообразования. Что заставляет пересматривать отношение и подходы к Форме в практике дизайна. Соотнесение современных проблем Формы с концепциями русского авангарда указывают пути получения ответов на вопросы о Форме в новых условиях, задают алгоритм действий по нахождению этих ответов.

Формостроение имматериальной субстанциональности осуществляется в образно-эмоциональном поле проектирования. Человек - носитель формальных качеств. Форма-матрица, при условии сохранения структурных особенностей 
человека как биологического вида и будет рождать «новые» формы «новой» реальности.

\section{Литература:}

1. Бодрийяр Ж. Система вещей / Ж.Бодрийяр. - М.: Рудомино, 1995. - 173 c.

2. Глазычев В. Дизайн как он есть. / Издание второе, дополненное. // М.:Европа - 2006.

3. Жирякова А.Д. «Форма. «Ноль-форма». Новая форма». Доклад на Международной научной конференции к 190-летию МГХПА имени С.Г. Строганова и к 100-летию П. А. Тельтевского «Теория искусства, традиционная культура и творческий процесс» Москва, Московская государственная художественно - промышленная академия им. С.Г. Строганова, 20.03. 2015 г.

4. Жирякова А.Д., Назаров Ю.В. Контекстные проблемы формообразования в дизайне / Декоративное искусство и предметно-пространственная среда. Вестник МГХПА // Московская Государственная ХудожественноПромышленная Академия им. С.Г. Строганова. Москва, №2 , 2015

5. Жирякова А.Д., Назаров Ю.В. Мироздание и жизнеустройство в концепциях формообразования К.С. Малевича и В.Е. Татлина / А.Д. Жирякова, Ю.В. Назаров // Вестник Оренбургского государственного университета. — Оренбург: ОГУ, 2015. — № 1.

6. Жирякова А.Д., Назаров Ю.В. Пластическое и тектоническое формообразование (в поисках смысла, различий и совпадений) // Дизайн и Технология. — 2014. — № 42 (84).

7. Маринетти Ф.Т. Первый манифест футуризма / Ф.Т. Маринетти // Называть вещи своими именами: Прогр. выступления мастеров запад.европ. лит. ХХ в. - М.: Прогресс, 1986.

8. Сидоренко В.Ф. Генезис проектной культуры и эстетика дизайнерского творчества. Автореферат дис. на соиск. уч. степ. док. искусствознания. 17. 00 06. Техническая эстетика и дизайн. - М., 1990. 
9. Татлин В.Е. Мастера советской архитектуры об архитектуре. Избр. отрывки из писем, статей, выступлений и трактатов. В 2-х т. Под общ. ред. М. Г. Бархина [и др.] Т. 2. Советская архитектура. Сост. : М. Г. Бархин и Ю. С. Яралова. М., «Искусство», 1975.

10. Хан-Магомедов С. О. Архитектура советского авангарда: В 2 кн. : Кн. 1: Проблемы формообразования. Мастера и течения. - М. : Стройиздат, 1996. - 709 с. : ил.

11. Klaus Kemp, Jonatan Ive (Foreword). - Leipzig. - 2011

12. Novoselov K. S. et al "Electric Field in Atomically Thin Carbon Films". Science 306, 666 (2004).

13. Rams Diter. As Little designe as Possible. .[Текст].// Sophy Lovell, Klaus Kemp, Jonatan Ive (Foreword). - Leipzig. - 2011

14. Stark Superstar! [Текст] // Архи Дом. - 2004.- № 8(49). 